\title{
Some new developments in radiation curing
}

\author{
K W Allen, E S Cockburn, R S Davidson*, K S Tranter and H S zhang \\ Department of Chemistry, City University, Northampton Square, \\ London EC1V OHB, UK.
}

\begin{abstract}
Decomposition of cationic photoinitiators in the solid state is used in a remote cure process ie. one in which photoinitiator is not present in the polymerisable monomer. An application of this process to a dual cure system is described. Details are given of free radical polymerisation reactions in aqueous solutions which produce latexes via both suspension and emulsion polymerisation processes. Finally, ways of improving the photosensitivity of poly (vinyl alcohol) modified with styrylpyridinium groups utilising mixed [2+2]cycloaddition reactions are described.
\end{abstract}

\section{INTRODUCTION}

Radiation curing refers to polymerisation induced by radition eg. electron beam, visible or ultraviolet light. Of particular value is the transformation of a liquid into a solid and this finds application in the surface coatings industry, imaging and even dentistry [1]. The most popular systems are totaliy solvent free although water borne systems are increasing in importance. Polymerisation reactions employed include free radical, cationic, anionic and cycloaddition processes with the latter two processes being dealt with in more detail by Professor J H J Frechet [3] and Dr A Reiser respectively.

\section{A CATIONIC CURING SYSTEM: THE REMOTE CURE PROCESS}

Photoinduced cationic curing of epoxides and vinyl ethers which involve the photogeneration of Lewis/Bronsted acids is well documented [4]. The most popular photoinitiators are onium salts (iodonium and sulfonium salts) although the recently introduced ferrocenium salt $\left(n^{5}\right.$ 2,4 -cyclopentadien-1-yl) $[(1,2,3,4,5,6-n)$-(methylethylbenzene) $]$ iron $\left(1^{+}\right)$hexafluorophosphate $\left.\left(1^{-}\right)\right)$is gaining popularity. Recent work has shown that onium salts decompose homolytically [4] and heterolytically $[5,6]$. Germane to our own work, was the finding that iodonium salts can generate acid via an intramolecular process $[6,7,8]$ thereby eliminating the need to involve a solvent.

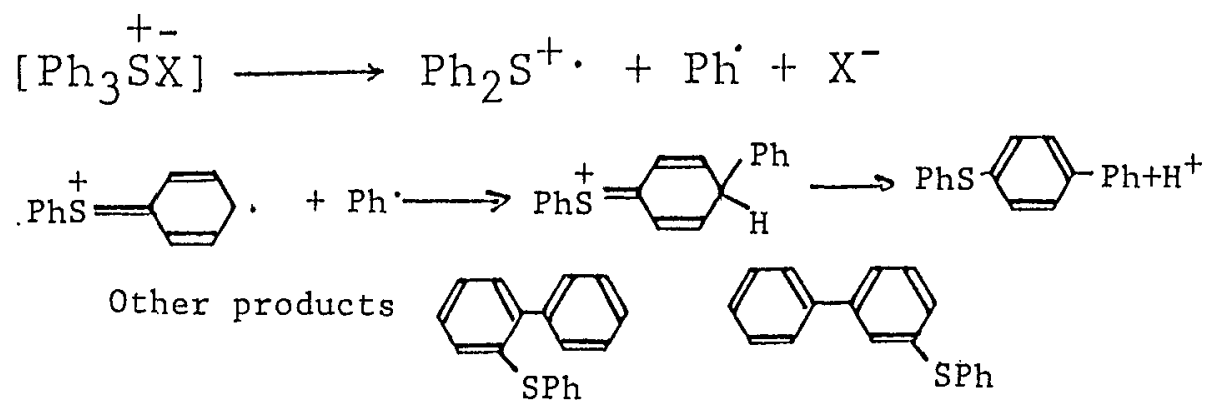

\footnotetext{
* Current Address: The Chemical Laboratory, University of Kent, Canterburv, Kent, CT2 $7 \mathrm{NH}$.
} 


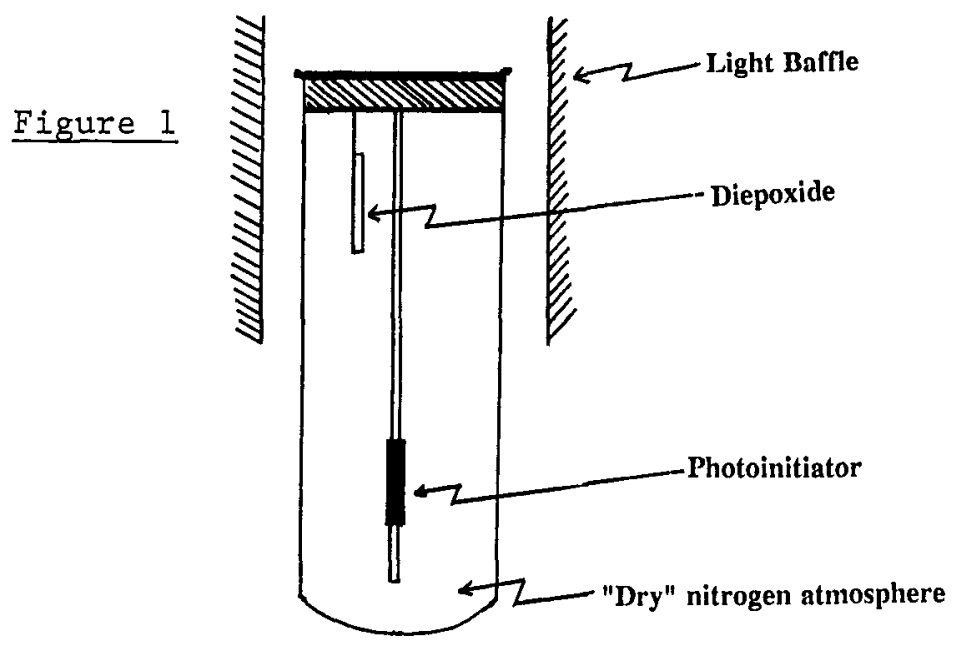

Hexafluorophosphate salts are commonly used and hexafluorophosphoric acid has been claimed to be the initiating species despite the fact that it is known to be unstable in organic media [9]. We have shown that electron beam and uv. induced fragmentation of onium hexafluorphosphate leads to decomposition of the hexafluorophosphate anion and have proposed that this leads to the production of hydrogen fluoride [10]. By use of the equipment

$$
\mathrm{HPF}_{6} \rightleftarrows \mathrm{HF}+\mathrm{PF}_{5}
$$

shown in Figure 1 we have demonstrated that onium salts, in the solid state photolyse to give a gas which induces polymerisation of the epoxide. Infrared studies confirm that hydrogen fluoride is evolved. These observations led us to design a "remote cure system" in which an onium, or ferrocenium hexafluorophosphate is irradiated to produce hydrogen fluoride which traverses a small gap to initiate polymerisation of an epoxide or vinyl ether [11] (Fig 2). of the many factors which influence the efficiency of this process, the magnitude of the gap, the nature of the support and the surface density of the initiator are important. The ferrocenium salt is very efficient and we found this surprising since the accepted mechanism for its decomposition requires the involvement of the polymerisable monomer (epoxide) $[12,13]$.

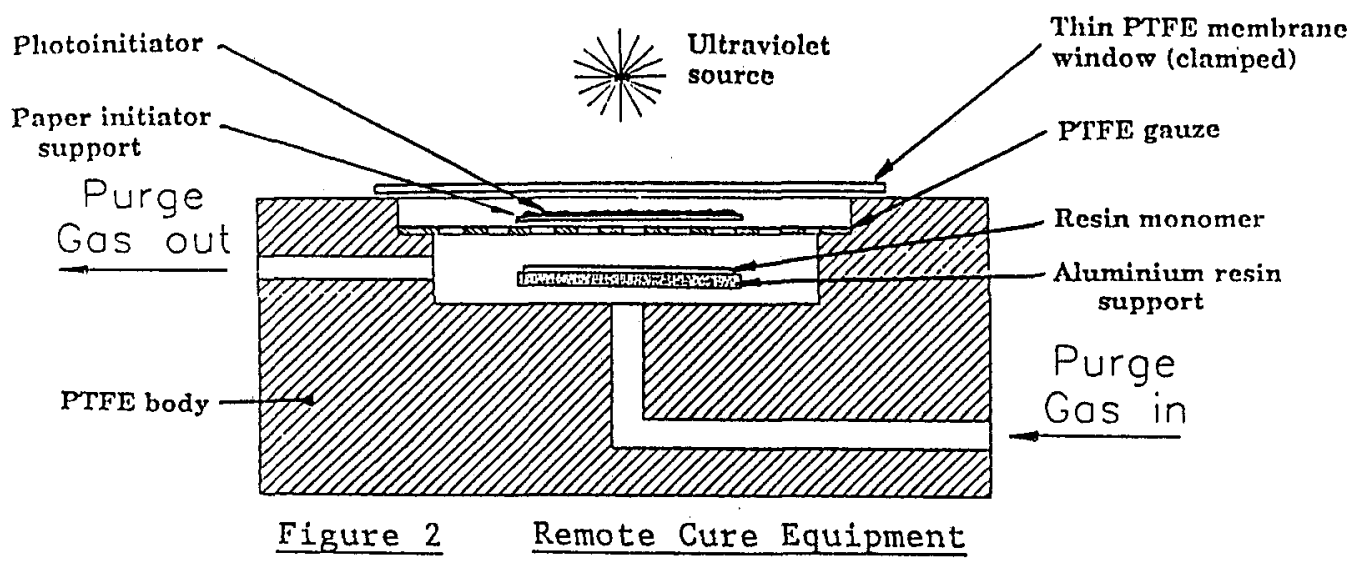

An application of the remote cure system is to dual cure. Thus a mixture of an epoxide, an acrylate and a Type I free radical initiator on exposure to hydrogen fluoride in the remote cure process leads only to the polymerisation of the epoxide. If this is followed by exposure to light, the acrylate is then polymerised. This sequence of events may be reversed. The processes can be conveniently monitored by infrared spectroscopy (Fig 3 ). 


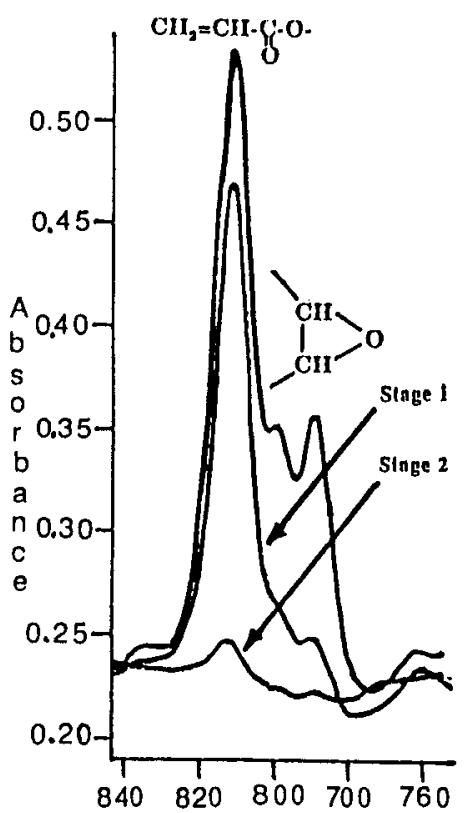

Dual Cure Type A

Stage 1: Epoxy Polymerisation Indirect Stage 2:Radical Polymerisation Direct

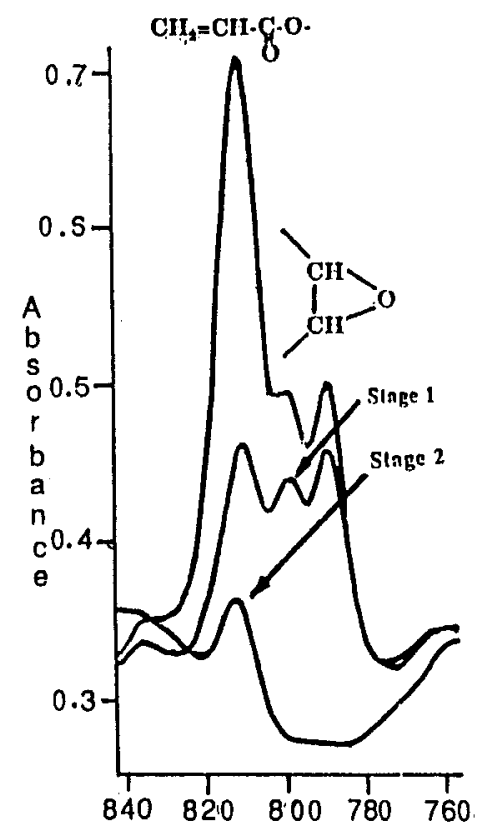

Dual Cure Type $B$

Stage 1:Radical Polymerisation Direct 3 tage 2: Epoxy Polymerisation Indirect Fig 3

\section{FREE RADICAL POLYMERISATION IN AQUEOUS SOLUTION}

Polymerisable monomer to be dispersed in the aqueous phase and in the case of emulsion polymerisation this is achieved by use of a surfactant. An important distinction between the two is that in suspension polymerisation several free radicals may be present in an oily droplet whereas in emulsion polymerisation only one radical is present in the growing latex particle. As a consequence suspension polymerisation leads to lower molecular weight polymers having a greater polydispersivity than those produced via emulsion polymerisation.

We have studied the heterogeneous photopolymerisation of acrylates by employing a whistle reactor (Fig 4) [16], which produces a suspension ultrasonically in combination with a conventional photochemical reactor. By use of oil soluble photoinitiators eg. benzoin methyl ether the products should be akin to those derived via a suspension process whereas with a water soluble photoinitiator system products similar to those produced by emulsion polymerisation may be obtained. Several water soluble ketones [2b] eg. sodium benzophenone-4-methyl sulphonate are available and these may be used in conjunction with an amine to provide an initiator system.

$$
\begin{aligned}
& \mathrm{Ar}_{2} \mathrm{CO}_{\mathrm{SO}} \stackrel{\mathrm{h \nu}}{\longrightarrow} \mathrm{Ar}_{2} \mathrm{CO}_{\mathrm{S} 1} \longrightarrow \mathrm{Ar}_{2} \mathrm{CO}_{\mathrm{T} 1} \\
& \mathrm{Ar}_{2} \mathrm{CO}_{\mathrm{T} 1}+\mathrm{RCH}_{2} \mathrm{NR}_{2} \longrightarrow \mathrm{Ar}_{2} \dot{\mathrm{COH}}+\mathrm{RCHNR}_{2} \\
& \dot{\mathrm{RCHNR}}_{2}+\mathrm{Acrylate} \longrightarrow \text { Polymer }
\end{aligned}
$$

The benzoin methyl ether initiated polymerisation of 2 -ethylhexyl acrylate in water produced latexes having an average particle size of $3.5-4.0 \mathrm{~m}$ and a high polydispersivity. When sodium benzophenone-4methyl sulphonate was used in conjunction with N-methyldiethanolamine as an initiator system a latex was obtained which showed a bimodal molecular weight distribution. Use of other amine synergists (Table 1) had a profound effect upon reaction time and the physical properties of the latexes, and of particular note was the molecular weight distribution (Fig 5). 


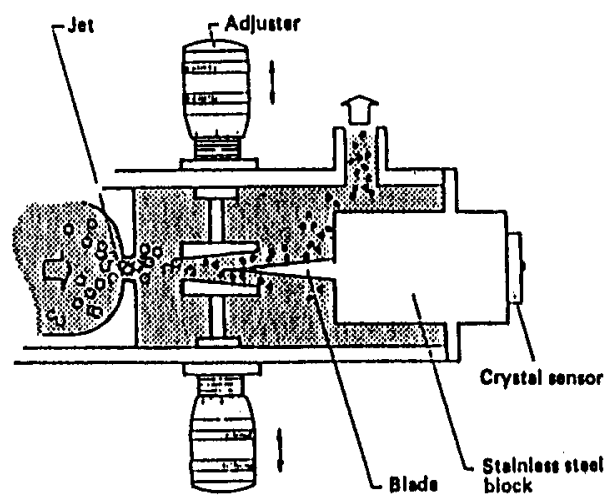

Fig 4

Diagram of a Whistle Reactor

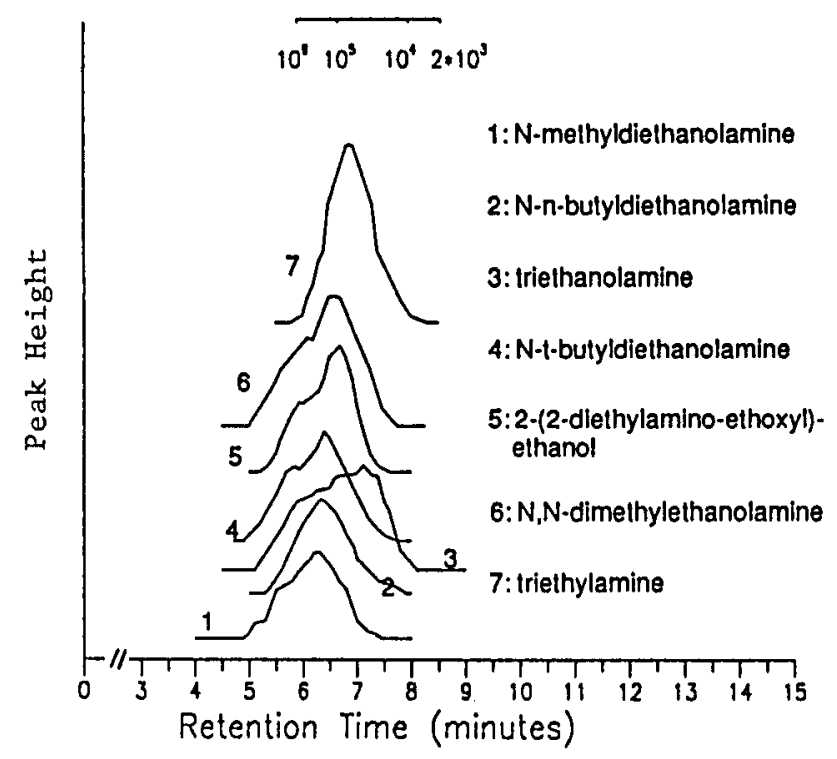

Fig 5 GPC Traces of Polymers Produced by Emulsion Polymerisation of 2-Ethylhexy1 Acrylate With Various Amine Synergists

The hydrophilicity of the amine has an effect upon this distribution and the larger this is, the greater the proportion of high molecular weight species. We conclude that the use of the "water soluble" Type II photoinitiator system may lead to some emulsion polymerisation but the dominant process is still suspension polymerisation.

\section{A WATER DEVELOPABLE IMAGING SYSTEM USING A [2+2] CYCLOADDITION}

[2+2] Cycloaddition reactions have found application in imaging [17] with the cyclodimerisation of cinnamic acid and its derivatives being particularly favoured [18]. Styrylpyridinium compounds also undergo $[2+2]$ cycloaddition reactions $[19,20]$ and these have been used to make a photoresponsive poly(vinyl alcohol) [20]. A valuable feature of this system is that it is aqueous developable. For [2+2] cycloaddition processes to be effective, the reaction partners have to be sited close to each other. When poly(vinylalcohol) is modified with 1-methyl-4-[2(4-formylphenyl) ethenyl] pyridinium methosulphate a photosensitive polymer is produced which exhibits excimeric fluorescence. Irradiation of the films led to the disappearance of this fluorescence. The observation of excimer emission points to aggregation of the pyridinium species in the film and we have suggested that reaction occurs via an

Table 1 Some Characteristics of the Polymers Produced by Emulsion Polymerisation Using Different Amine Synergists

AMINE

Triethylamine

2-(2-Diethylamino-ethoxy) - ethanol

$\mathrm{N}-\mathrm{n}$-Butyldiethanolamine

N-t-Butyldiethanolamine

$\mathrm{N}-\mathrm{n}$-Dimethylethanolamine

N-Methyldiethanolamine

Triethanolamine

N, N-Bis (2-hydroxyethyl)-p-toluidine

2-Diethylaminoethyl acrylate

$\begin{array}{llcl}\text { REACTION } & \text { YIELD } & \text { MEAN } & \text { WEIGHT } \\ \text { TIME } & (\%) & \text { PRACTICE } & \text { AVERAGE } \\ \text { (mins) } & & \text { SIZE } & \text { MOLECULAR } \\ & & (\mathrm{m}) & \text { WEIGHT }\end{array}$

60

50

60

80

60

60

60

80

80

\begin{tabular}{rlr}
83.0 & 3.47 & 140,000 \\
50.0 & 2.36 & 558,000 \\
85.0 & 2.36 & 611,000 \\
62.3 & 2.87 & $1,094,000$ \\
88.4 & 3.57 & 700,000 \\
78.0 & 3.64 & $1,460,000$ \\
80.7 & 5.80 & 539,000 \\
5.0 & Unstable \\
18.0 & Unstable \\
\hline
\end{tabular}


excimer [21]. Thus, like the cycloaddition reaction of enones [22] the crosslinking is occurring via attack of an excited species upon a ground state species in which the latter provides a suitable double bond. We have therefore examined the possibility of carrying out mixed cycloadditions in which the poly (vinylalcohol) is functionalised with a styrylpyridinium group and an unsaturated aldehyde. A poly(vinylalcohol) carrying pendant styrylpyridinium groups was mixed with poly(vinylalcohol) which had been reacted with 3-(2-furyl)acrolein. Films were prepared from the mixture and exposed to light. The presence of the acrolein increased the sensitivity of the film. Fluorescence spectra of such films showed emission from the styryl-pyridinium compound in its monomeric state and this emission decreased in intensity when the film was exposed to light. We concluded from these and other observations that a mixed cycloaddition process was leading to insolubilisation of the poly (vinylalcohol). That this process did not involve the furan ring [23] was shown by the finding that poly (vinylalcohol) modified with furfuraldehyde did not increase the sensitivity of the styrylpyridinium salt modified poly(vinylalcohol).

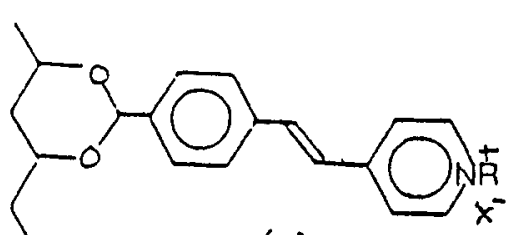

(1)

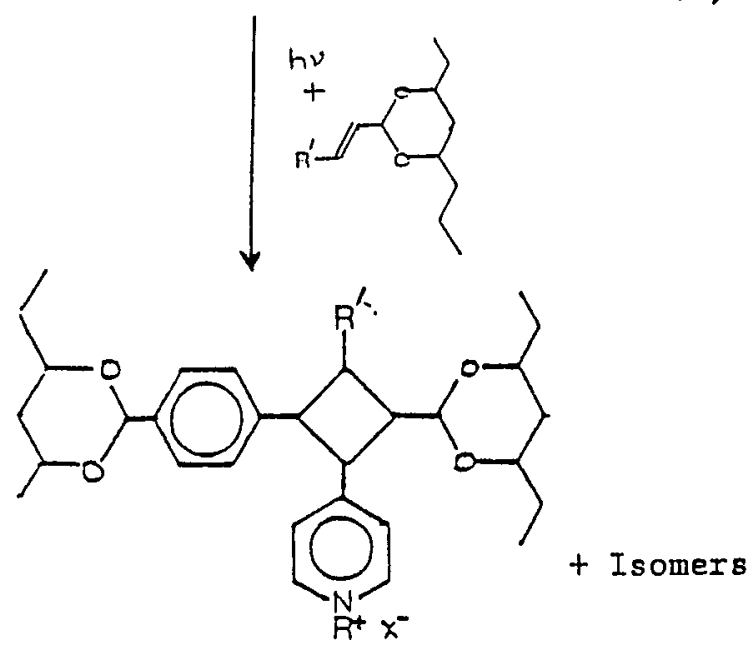<smiles>[Y][R]1ccc(C2C(c3ccc(C4OC(C)CC(CC)O4)cc3)C(c3ccncc3)C2c2ccc(C3OC(C)CC(CC)O3)cc2)cc1</smiles>

+ Isomers

$$
\begin{aligned}
\mathrm{R}^{\prime} & =\prod_{0} \\
& =\mathrm{H}^{+}- \\
& =\mathrm{CH}_{3}- \\
& =\mathrm{CH}_{3} \mathrm{CH}^{-}=\mathrm{CH}^{+}-
\end{aligned}
$$

\section{MIXED CYCLOADDITION}

The scope of the mixed cycloaddition process has been extended by the use of acrolein, crotonaldehyde and 2,4-hexadienal in place of the furylacrolein. These findings open up further opportunity for producing photosensitive poly (vinylalcohols).

\section{Acknowledgements}

We thank the British Technology Group for financial support for the projects on remote cure and free radical polymerisation in aqueous solution, and the Science and Engineering Research Council for a CASE Award (ESC). Work on the poly(vinylalcohol) systems was a joint venture with the sericol Group Ltd and in particular valuable contributions were made by Drs $J \mathrm{H}$ Hamilton and $\mathrm{J} \mathrm{E}$ Pratt.

\section{REFERENCES}

1. R S Davidson and M Salim in "Chemistry and Technology of UV and EB Formulation for coatings, Ink and Paints", Ed. P K T oldring, SITA Technology Ltd, London, 1991, chapt 3, 217.

2a. R Arnoldus, Radtech Europe '89, Radtech Switzerland 1989, 121.

b. P N Green and A Green, Radtech Europe '89, Radtech Switzerland, 1989,383 . 
3. J F Cameron and J M J Frechet, J Org Chem, 1990, 55, 5919.

$J$ M J Frechet and J F Cameron, Polym Mater Sci Eng, 1991, 64, 55. $J \mathrm{~F}$ Cameron and $J \mathrm{M} J$ Frechet, J Amer Chem Soc, 1991, 113, 4303 . See also W Mayer, $H$ Rudolf and $E$ de Cleur, Angew Makromol Chem, $1981, \underline{93}, 83$.

4. S P Pappas, "UV Curing: Science and Technology", Vol I and II, Technology Marketing Corporation, Stamford Conn, USA, 1978, 1985.

5. R S Davidson and $J \mathrm{~W}$ Goodin, Eur Polym J, 1982, 18, 1.

6. N P Hacker and K M Welsh, Macromolecules, 1991, 24, 2137.

7. J L Dektar and N P Hacker, J Org Chem, 1990, 55, 639.

$J$ I Dektar and N P Hacker, J Amer Chem Soc, 1990, 112, 6004.

$F$ D Saeva and D T Breslin, J Org Chem, 1989, 54, 712.

$F$ D Saeva, D T Breslin and H R Luss, J Amer Chem Soc, 1991, 113, 5333 .

8. N P Hacker, D V Leff and J I Dektar, Mol Cryst Liq Cryst, 1990, 183,505 .

9. Kirk-Othmer "Encycl Chem Tech" (3rd Edn) Wiley, Chichester, 1980, 10. 780 .

10. R S Davidson and S A Wilkinson, J Photochem Photobiol A, 1991, 58, 123.

11. R S Davidson and S A Wilkinson UK Patent Appln 223,5199, A.

12. D R Chrisope, K M Park and G B Schuster, J Amer Chem Soc, 1989, 111,6195 .

13. H Zweifel and M Meier, Radcure Europe '85, Basle, Switzerland. Society of Manufacturing Engineers, Dearborn, Michigan, USA, Paper FC85-417.

14. E A Grulke in "Encyclopaedia of Polymer Science and Engineering", $\mathrm{J}$ Wiley \& Sons Inc, NY, 1989, Vol 16, 443.

15. W Cooper in "Reactivity, Mechanism and structure in Polymer Chemistry", Ed A D Jenkins and A Ledwith, 1974, J Wiley \& Sons, London chapt 7,175 .

16. R S Davidson, A Safdar, J D Spencer and B Robinson, Ultrasonics, $1987,25,35$.

17. G E Green and B P Stark, J Macro Sci - Revs Macromol, Chem, 1982, $\mathrm{C} 21,187$

A Reiser, "Photoreactive Polymers: The Science and Technology of Resists", Wiley Interscience, NY, 1989.

I M Minsk, J G Smith, W P Van Deusen and J F Wright, J Appln Polym Sci, 1959, 11, 302 .

18. Eastman Kodak Co, 1959, British Patent 813,604.

Harris Intetype, 1968, British Patent 1,112,277.

A A Lin and A Reiser, Macromolecules, 1989, 22, 3898

A A Lin, C F Chu and A Reiser, Macromolecules, 1990, 23, 36161.

19. J L R Williams, 1959, US Patent 2,908,667.

J L R Williams and D G Borden, Makromol Chem, 1964, 73, 203.

20. K Ichimura and $\mathrm{S}$ Watanabe, J Polym Sci, Polym Chem Ed, 1982, 20, 1419 .

K Ichimura, J Polym Sci, Polym Chem Ed, 1982, 20, 1411 and $1987, \underline{25}, 3063$.

21. E S Cockburn, $R$ S Davidson, $S A$ Wilkinson and J Hamilton, Eur Polym J, 1988, 24, 1015 .

22. P E Eaton, Accounts of Chem Res, 1968, 1, 50.

23. O Nuyken, $\mathrm{K}$ Budde and $\mathrm{F}$ Quella, Radcure Europe '87, Munich. Society of Manufacturing Engineers, Dearborn, Michigan, USA, Paper 9-29. 